\title{
FINE SPATIAL SCALE MODELLING OF TRENTINO PAST FOREST LANDSCAPE (TRENTINOLAND): A CASE STUDY OF FOSS APPLICATION
}

\author{
S. Gobbi ${ }^{1,2,3 *}$, M.G. Cantiani ${ }^{1}$, D. Rocchini ${ }^{2,4,6}$, P. Zatelli ${ }^{1}$, C. Tattoni ${ }^{1}$, N. La Porta ${ }^{3,5}$, M. Ciolli ${ }^{1,3}$ \\ ${ }^{1}$ University of Trento, Dep. of Civil, Environmental and Mechanical engeneering, Trento, Italy \\ (stefano.gobbi, maria.cantiani, paolo.zatelli, clara.tattoni, marco.ciolli)@unitn.it \\ ${ }^{2}$ Fondazione Edmund Mach, San Michele allAdige (TN), Italy - duccio.rocchini@fmach.it \\ ${ }^{3}$ The EFI Project Centre on Mountain Forests (MOUNTFOR), San Michele a/Adige, Trento, Italy \\ ${ }^{4}$ Centro Agricoltura, Alimenti e Ambiente, San Michele allAdige (TN), Italy \\ ${ }^{5}$ IASMA Research and Innovation Centre, Fondazione Edmund Mach, San Michele a/Adige, Trento, Italy - nicola.laporta@ fmach.it \\ ${ }^{6}$ Centro Biologia Integrata (CIBIO), University of Trento
}

Commission IV, WG IV/4

KEY WORDS: Remote sensing, mapping, orthophotos, GRASS GIS, QGIS, Trentino, Forestry, Ecology

\begin{abstract}
:
Trentino is an Italian alpine region (about $6200 \mathrm{Km}^{2}$ ) with a forest coverage exceeding $60 \%$ of its whole surface. In the past, forest landscape has changed dramatically, especially in periods of forest over-exploitation.

Previous studies in some Trentino sub-regions (Val di Fassa, Paneveggio) have identified these changes and the current trend of forest growth at the expenses of open areas, such as pastures and grasslands, due to the abandonment of rural areas. This phenomenon leads to the rapid Alpine landscape change and profoundly affects the ecological features of mountain ecosystems. To be able to monitor and to take future actions about this trend it is fundamental to know in detail the historical situation of the progressive changes on the land use that occurred over Trentino.

The work aims to comprehensively reconstruct the forest cover of whole Trentino at high resolution ( $5 \mathrm{~m} \times 5 \mathrm{~m}$ pixels) using a series of maps spanning a long period, consisting in historical maps, aerial images, remote sensed information and historical archives. The datasets were archived, processed and analyzed using the Free and Open Source Software (FOSS) GIS GRASS and QGIS. Historical maps include Atlas Tyrolensis (dated 1770), Theresianischer Kataster (dated 1859) and Italian Kingdom Forest Map (IKFM) of 1936. The aerial imagery dataset includes aerial images taken in 1954, which have been orthorectified during this research, and orthophotos available for years 1973, 1994, 2000, 2006, 2010 and 2016. Remote sensed information includes Landsat and recent Lidar data, while historical archives consist mostly in Forest Management Plans available since around 1950.

The versatility of the wide variety of modules supplied from the FOSS GRASS and QGIS enabled to perform a diverse set of analysis and pre-processing (e.g.:orthorectification) on a heterogeneous dataset of input images. We will focus on the different strategies and methodologies implemented in the FOSS GIS used to process the various types of geographic data, challenges for the future of the research and the fundamental role of the FOSS systems in this process.

Quantifying forest change in the time-span of our dataset can be used to perform further analysis on ecosystem services, such as protection from soil erosion, and on modification of biome diversity and to create future change scenarios.
\end{abstract}

\section{INTRODUCTION}

Provincia Autonoma di Trento (PAT or Trentino) is an alpine region of the north of Italy. Its surface is about $6200 \mathrm{~km}^{2}$, with a strong presence of forests, characterized by a variety of different types. In fact, the presence of the Alps shaped a whole variety of different habitats: while the lowest point of PAT is at 64 m.a.s.l. (Valle del Sarca) the highest point is Monte Cevedale (3769 m.a.s.1.) (Sitzia, 2009). The importance of the natural environment in Trentino is underlined by the presence of a national park (Parco Nazionale dello Stelvio), two regional parks (Parco dell'Adamello Brenta, Parco delle dolomiti di Paneveggio) and 142 habitats in the Natura2000 network.

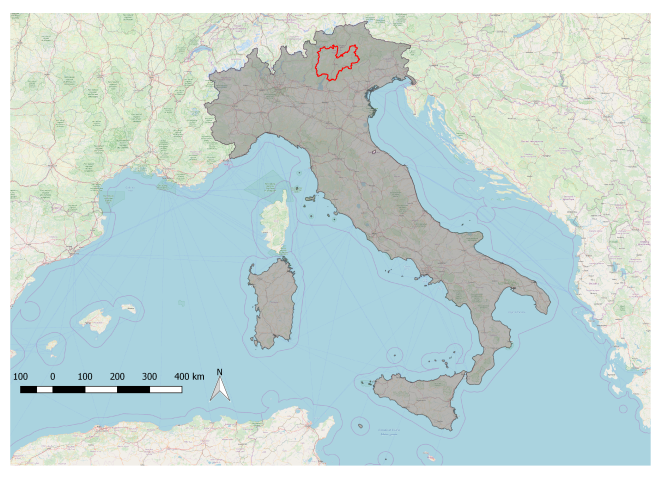

Figure 1. The position of Trento Province within the Italian territory

* Corresponding author 
Forest in PAT are characterized by a strong presence of coniferous species, mostly spruce (Servizio Fauna e Foreste, 2018).

\section{Forest types in Trentino}

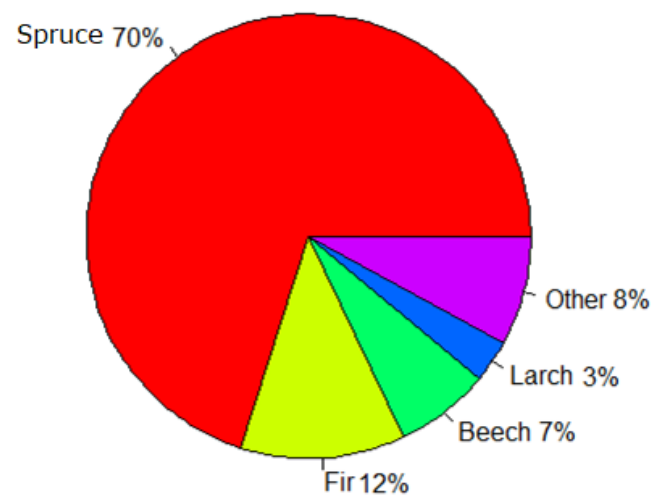

Figure 2. Principal forest types in PAT (Servizio Fauna e Foreste, 2018)

During the centuries human activities has shaped the Trentino landscape. While activities such as timber harvesting and agriculture, which required to be near the townships, shaped the valley bottoms, the traditional "malga" system for pasture shaped the high mountain meadows (MacDonald et al., 2000).

During World War I the position of Trentino was strategical for both the Austro-Hungaric Empire and the Italian Kingdom, so Trentino was the ground for long and weary battles. In this period both the involved armies exploited heavily the timber, contributing to the deforestation of the Alps (Tattoni et al., 2010). After World War II the socio-economical situation changed again: extreme poverty pushed people to leave villages in the valleys towards the two main towns (Trento and Rovereto), abandoning the traditional agricultural and pastoral activities, consequentially abandoning meadows and crop fields to a progressive afforestation (De Natale et al., 2005), (Sitzia et al., 2007), (Sitzia, 2009), (Tattoni et al., 2017).

All these changes favored some types of habitats and some tree and animal species, while other species were negatively influenced by the abandonment of human activities in the mountains (Tattoni et al., 2010). The problem is not just concerning the PAT region, but it is recognized at a European Level: the Pan-European biological and landscape diversity strategy, the Bern Convention, the European Landscape Convention, the Birds and Habitats Directives are some of the acts taken by the European Union to preserve high mountain landscapes (Cantiani et al., 2016).

In this framework it becomes crucial the knowledge of past forest landscape in PAT, in order to identify the evolution and the rate of change of some specific habitats through the investigated territory (Ciolli et al., 2012). A multi-temporal map analysis was carried out in the whole Trentino territory. In part 2 we will explain more in detail the features of the datasets involved, which cover a time span from 1859 to 2015 . The Free and Open Source Software for Geography GRASS GIS has been used, exploiting its multi-purpose potential to process such a diverse and wide variety of data, as explained in parts 2 and 4 . Focus of the current work will be given on the GRASS module used, while some already published results for limited areas of
Trentino will be presented, to show how this kind of study can address political and environmental decision over the conservation of specific habitats (Ministero dell'ambiente, 2010).

\section{MATERIALS AND METHODS}

The availability of aerial and satellite imagery in recent years and the development and free distribution of powerful GIS software made easier to perform remote sensing inquires over a specific territory (Rocchini et al., 2012) (Tattoni et al., 2010) (Neteler, Mitasova, 2008). Techniques such as image classification are a consolidated method for studying multi-temporal forest evolution (Gaitanis et al., 2015) (Godone et al., 2014) (Gautam et al., 2004).

Here we will briefly present the cartographic data used and the algorithm implemented to carry out the analysis of PAT territory over the years.

\subsection{The 1859 cadastrial maps}

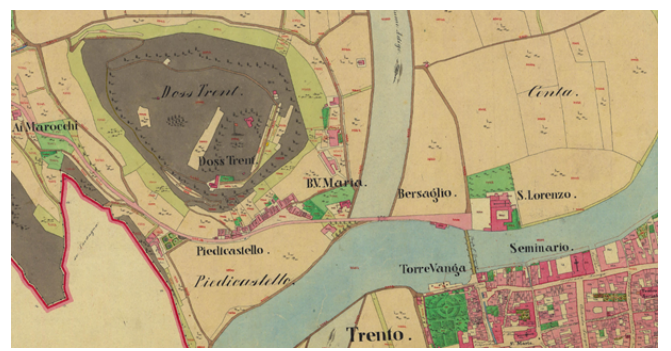

Figure 3. An example of the 1859 maps: the depiction of the town of Trento.

The Austro-Hungaric cadastre was drawn by the Imperial edict of Franz Joseph I von Österreich in 1817. The part of PAT was completed in 1859 and it is divided in sheets (13300 sheets, approximately), in scale 1:2880 (Servizio Catasto della Provincia Autonoma di Trento, 2019a). In 2006 the procedure of digitalization and georeferentiacion of the whole cadastre was completed. Each sheet is available in UTM32N-ETRS89 reference system and JPG format (Servizio Catasto della Provincia Autonoma di Trento, 2019b). The map represents a thematic map; areas with different colours represent different land use (figure 4):

1. grey for the forests;

2. light green for the private/public pastures;

3. green for the crops;

4. blank for the unproductive lands.

Water bodies, construction and roads are as well clearly recognizable and, if they are relevant, named. Information about the density and type of forests are missing. 


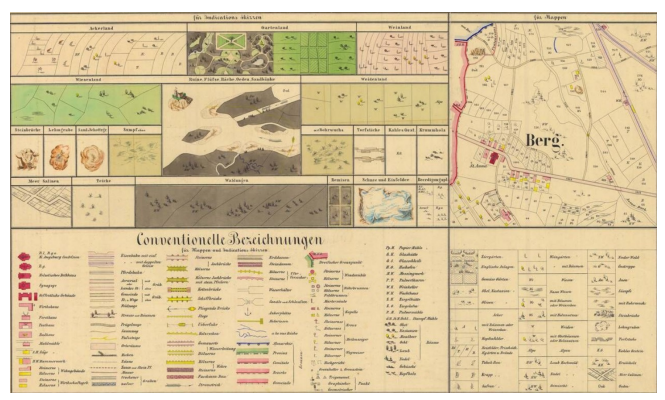

Figure 4. The legend for the 1859 cadastrial maps (in German).

\subsection{The 1936 Italian Kingdom Forest Map}

The Italian Kingdom Forest Map (IKFM) was produced in 1936 by the Milizia Italiana Forestale, to map the presence of forests in the Italian territory. The cartographic base was the map in scale 1:100 000 produced by the Istituto Geografico Militare Italiano, now available in one of the Gauss-Boaga/Rome40 datum two zones (west and east, EPSG 3003 and 3004), depending on the map sheet location (Ferretti et al., 2018).

This map is considered the first example of forest and forest types mapping for the whole Italian Territory (Ferretti et al., 2018). In fact the legend reports a total of 25 different forest types (Ferretti et al., 2018).

The IKFM was digitalized to be preserved and consulted freely. Each sheet was scanned and georeferenced in a TIFF format. Each sheet has an approximate dimension of $112 \mathrm{MB}$, with a resolution of $400 \mathrm{ppi}$ (pixel per inch); as for the georeferencing process it was decided to keep the original Gauss-Boaga RM40 reference system (Ferretti et al., 2018). The map has been classified and vectorized by manually digitizing each forest patch (Ferretti et al., 2018). The resulting map is available under the Creative commons Attribution - Version 3.0 license and can be viewed and downloaded from a dedicated webgis (Ferretti et al., 2019).

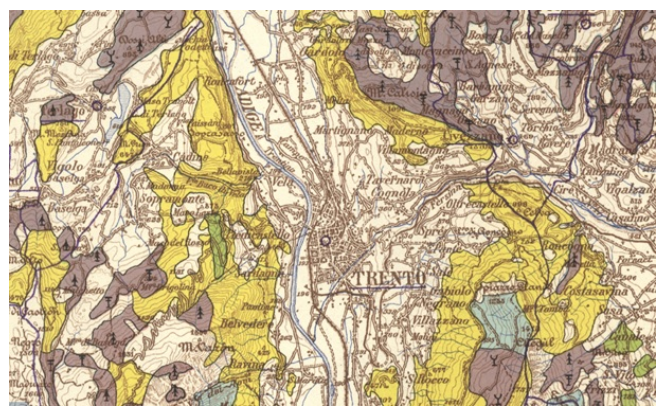

Figure 5. An example of the 1936 maps: the depiction of the town of Trento.

\subsection{The single band aerial imagery of PAT}

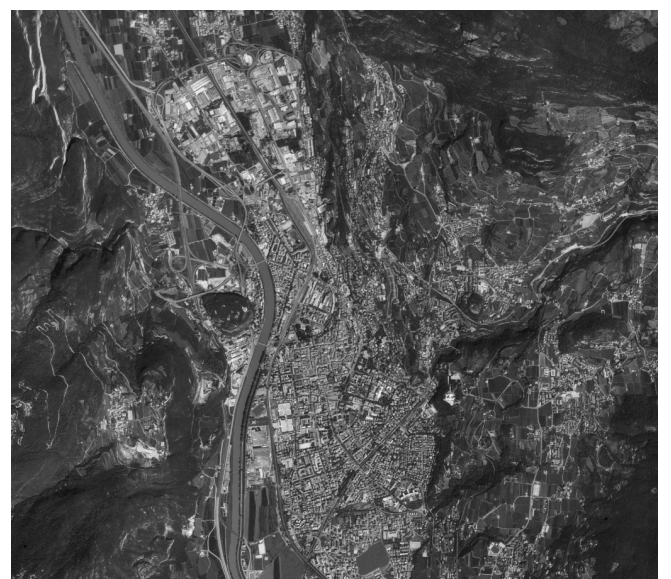

Figure 6. An example of the 1994 aerial images: the depiction of the town of Trento.

To perform the current study different sets of imagery were chosen, in particular the images from 1954, 1973 and 1994 that are coded in single band greyscale. The set of aerial photographs from 1954 (denominated "Volo GAI", Gruppo Areonautico Italiano) in particular, has been orthorectified during this project, as explained in part 2.6. The table 1 shows details about resolution, datum and number of images used to depict PAT territory (Geoportale Provincia Autonoma di Trento, 2019a) (Geoportale Provincia Autonoma di Trento, 2019b).

\begin{tabular}{c|c|c|c} 
Year & Pixel dimension & Images in set & Datum \\
\hline 1954 & $2 \times 2 \mathrm{~m}$ & 229 & WGS84- UTM32N \\
1973 & $1 \times 1 \mathrm{~m}$ & 229 & Gauss Boaga-RM40 \\
1994 & $1 \times 1 \mathrm{~m}$ & 229 & Gauss Boaga-RM40
\end{tabular}

Table 1. Features of the greyscale sets of imagery of Trentino region, pixel dimension on the ground.

\subsection{The multi-band aerial imagery of PAT}

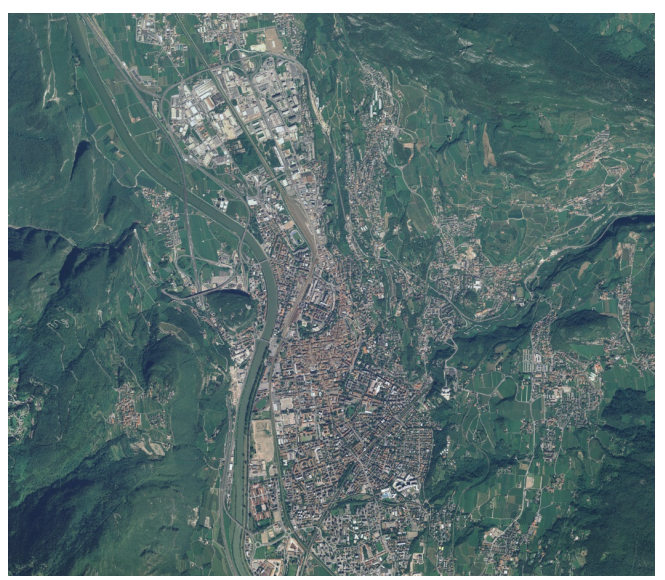

Figure 7. An example of the 2006 aerial images: the depiction of the town of Trento.

The multi band imagery of PAT used in the current work were taken in 2006 and 2015. Table 2 reports details about resolution, 
datum and number of images used to represent PAT territory (Geoportale Provincia Autonoma di Trento, 2019c) (Geoportale Provincia Autonoma di Trento, 2019d).

\begin{tabular}{c|c|c|c} 
Year & Pixel dimension & Images in set & Datum \\
\hline 2006 & $0.5 \times 0.5 \mathrm{~m}$ & 229 & WGS84- UTM32N \\
2015 & $0.2 \mathrm{mx} 0.2 \mathrm{~m}$ & 839 & WGS84- UTM32N
\end{tabular}

Table 2. Features of the multi-band sets of imagery of Trentino Territory, pixel dimension on the ground.

These newer images have a better geometric resolution and at least 3 bands (Red, Green and Blue). In particular the images of 2015 set include the additional near-infra-red band. The downside of this amount of additional information is the dimension on the computer memory required: while the dataset of 2006 has a dimension of approximate $100 \mathrm{~GB}$, the dataset of 2015 has a dimension of approximate $780 \mathrm{~GB}$.

\subsection{GRASS GIS}

GRASS GIS has been chosen to manage and perform the images processing. The software was first developed by the U.S. Army Construction Engineering Research Laboratories (USACERL, 1982-1995). Starting from 1999 to nowadays GRASS is released under a GNU license by the Open Source Geospatial Foundation (OSGeo) (Neteler, Mitasova, 2008). The architecture of GRASS is inspired by a modular structure, involving more than 350 different modules, which can be stacked together to perform complex analysis (Neteler et al., 2012). Single developers and researchers are welcome to study and develop new modules to fit their purposes (Preatoni et al., 2012), and they can be possibly saved in a on-line package repository, to be downloaded by other researchers all over the world. It is worth remembering that both the source code of GRASS and its modules are accessible: this fact is crucial to ensure robust analysis output (Rocchini et al., 2012) and and its suitability for educational purposes (Ciolli et al., 2017).

Moreover, GRASS can be scripted using Python programming language: this allows to stack different modules and apply identical procedures to a great number of input imagery (Van Rossum, 1995).

In the current work the versions of GRASS used are the 7.4 and the 6.4, as explained in part 2.6 (GRASS Development Team, 2017) (GRASS Development Team, 2018).

\subsection{Orthorectification of the datasets of $\mathbf{1 9 5 4}$}

Ortorectification is the process of adapting a flat image to a rugged and curved surface, by adapting the reference and projection system (Gobbi et al., 2018). In this case-study the dataset of 1954 imagery required this pre-processing because only the original images are available.

This process is performed in three different steps:

1. internal orientation to evaluate the position of the image with respect to the camera frame;

2. external orientation to evaluate the position of the camera with respect to the external reference system (the chosen datum);

3. orthorectification to re-project the image.
To perform the first step it is necessary to measure and identify the position of 4 or more fiducial markers on the original photograph. To perform the second step is necessary to set a consistent number of Ground Control Points, or points whose coordinates are known in both the reference systems of the original image and the target reference system (Novak, 1992). Finally the re-projection is performed using a set of equations, called collinearity equations, which rectify the original image by shifting, rotating and scaling each of its pixel (Novak, 1992) (Gobbi et al., 2018) (Rocchini et al., 2012). A DEM which describes the geometry of the ground surface must be available.

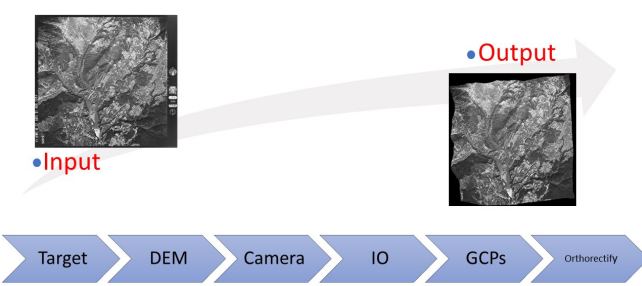

Figure 8. Flowchart of the modules and data in GRASS GIS for orthorectification.

In this study the versions used for orthorectification are the 6.4 and 7.4 versions. In fact the suite i.ortho.photo was removed from the versions between the 6.4 and the 7.2.

In GRASS 6.4 the process is divided in different steps:

1. i.target allows to chose a target reference system;

2. i.ortho.elev allows to set a Digital Elevation Model used to correct the position of points according to the orography;

3. i.ortho.camera allows to set the parameters of the camera which took the picture (e.g. the focal length);

4. g.gui.photo2image allows to input the position of the fiducial markers;

5. g. gui.image2target allows to input the position of the GCPs;

6. i.ortho.rectify performs the actual rectification.

After inserting manually the position of fiducial markers and GCPs it was possible to use Python to apply the orthorectification to a whole set of imagery inside a single mapset. It is possible to set a raster mask: this is useful if, as it is in this study, the original image has a frame, containing instruments reading, which must be removed in the orthorectified image.

Due to the user-friendly interface, GRASS 7.4 was chosen to perform the input of the GCPs: this choice was considered less time consuming than the using the old 6.4 GRASS. On the other hand GRASS 7.4 did not allow the setting of a mask for excluding some parts of the image (the frame, in our case study) therefore it was chosen to run the i.ortho.rectify command on GRASS 6.4 .

\subsection{Landuse classification algorithms}

To reconstruct the forest landscape it is necessary to perform a landuse classification for each dataset. This process generates a map where each "pixel" or "object" is grouped in a finite number of set, each one representing a type of land use. Typically 
there are 5 macro-categories: urbanized, forest, agriculture, water, unproductive.

There are two families of algorithm: the maximum likelihood family and the OBIA family.

The maximum likelihood algorithms require as input at least one area for each class of landuse, where the software running the algorithm calculates a statistical distribution of the spectral response of the pixels within the area. Then each pixel of the image is classified inside different macro-class by checking which class its spectral response statistically belongs to (Bouman , Shapiro, 1992).

Object-based Image Analysis (OBIA) takes a different approach: instead than classifying each single pixel, OBIA creates groups of pixels, called segments, which are classified as single objects using machine learning. The parameters used by the machine learning are the statistical distribution of the pixels radiometric response inside the single object and the geometry of the same object (perimeter, area, compact circle, compact square, fractal index) (Clewley et al., 2014). Each segment of pixels is called "object" and it is characterized by pixels with a similar spectral response. The choice between the two algorithm should be driven by the resolution of the input image. If the objects (houses, trees, roads, water bodies) depicted in the image are larger than the pixel resolution an OBIA approach is more likely to give a nicer, cleaner land use output map (Burnett, Blaschke, 2003). If the objects depicted are smaller than the resolution (e.g. the resolution 30x30m of some Landsat images) a maximum likelihood algorithm is preferable, because it is possible that similar pixels will be grouped inside the same object while in reality they depict two different things.

In the current case study the resolution of the aerial imagery is always smaller than the represented objects (tables 1 and 2) and the OBIA approach was preferred.

In GRASS the procedure is not coded as a suite of command as it was for the orthorectification process, so it was necessary to create a procedure which differs for the multi-band and the single band imagery (Grippa et al., 2017).

Some common steps are required:

\section{1. i.segment performs the segmentation of the imagery;}

2. r.texture r.texture evaluates the textural differences, this provides an additional band which give more information about each single object;

3. i.segment.stats evaluates the radiometric features of each segment and store them in the table associated to the (vector) output map;

4. v.class.mlR uses machine learning to classify the object inside the chosen land-use categories;

Figures 10 and 9 show the flowchart with the input data for the case of single band imagery $(1954,1973,1994)$ and colour imagery $(2006,2015)$. The textural measure was considered in both cases as additional image band, because where it is necessary to discriminate between forests and crop fields the spectral response is similar, but the textural measure within the same object differs, giving to the machine learning algorithm helpful data to discriminate the two situations (Haralick et al., 1973).

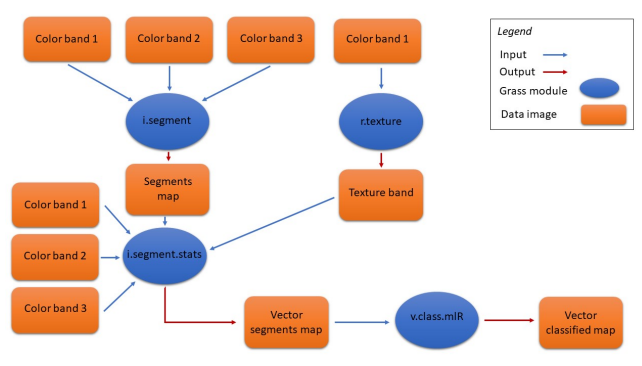

Figure 9. Flowchart of the modules and data in GRASS GIS for OBIA of multi-band images.

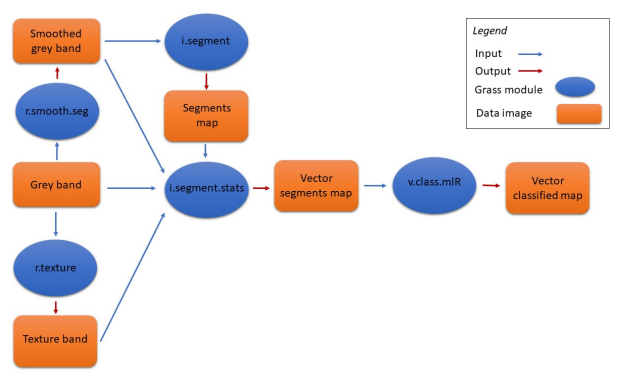

Figure 10. Flowchart of the modules and data in GRASS GIS for OBIA of single grey-band images.

The command r.smooth.seg, applied on the single band imagery performs a preliminary segmentation on the image by smoothing values of pixels within the same object and adding more contrast to the boundaries of the segments (Vitti, 2012). For this reason it was considered more reliable to apply this module to the image before using i.segment. The output from i.smooth.seg was used as input to the machine learning as well.

The procedure was scripted with Python and applied sequentially on each map inside the different datasets.

\subsection{Manual classification of 1859 cadastrial maps}

The dataset of 1859 is composed by 13300 sheets, and applying to each one of them a OBIA procedure for classifying the maps would have costed too much in terms of computational time. Instead the maps were classified using a manual procedure. The procedure was performed in GRASS version 7.4 and QGIS version 2.18 (QGIS Development Team, 2019), and involved the use the vectorizer instrument.

The vectorized areas where the ones indicated as "forest" (with attribute "1" in the attribute table), "pasture" (with attribute "2" in the attribute table) and "wooded pasture" (with attribute " 3 " in the attribute table). A few simple rules were followed:

1. if two or more neighbour cadastrial parcel had the same landuse they were digitized as one single area;

2. assign a single identifier value to each area;

3. digitize following the black border of each area and include the border in the area;

4. exclude lakes and rivers from the digitalization process. 


\begin{tabular}{c|c|c|c|c|c|c} 
Year & Denomination & Scale & Type of map & Pixel dimension & Dimension [GB] & Datum \\
\hline 1859 & Theresiascher Kadastrte & $1: 1440$ & Topographic map & $0.2 \times 0.2$ & 20 & ETRS89-UTM32N \\
1936 & Italian Kingdom Forest Map & $1: 100000$ & Topographic map & $0.32 \times 0.32$ & 1 & Gauss Boaga RM40 \\
1954 & Volo GAI & $1: 35000$ & Aerial images BN & $2 \times 2 \mathrm{~m}$ & 8 & WGS84- UTM32N \\
1973 & Volo Rossi-EIRA & $1: 10000$ & Aerial images BN & $1 \times 1 \mathrm{~m}$ & 8 & Gauss Boaga-RM40 \\
1994 & Volo Italia & $1: 10000$ & Aerial images BN & $1 \times 1 \mathrm{~m}$ & 8 & Gauss Boaga-RM40 \\
2006 & Volo Terraitaly & $1: 5000$ & Aerial images RGB & $0.5 \times 0.5 \mathrm{~m}$ & 100 & WGS84-UTM32N \\
2015 & Volo AGEA & $1: 5000$ & Aerial images RGB & $0.2 \times 0.2 \mathrm{~m}$ & 730 & WGS84-UTM32N \\
\hline
\end{tabular}

Table 3. The data collection for the current case-study.

\section{RESULTS}

A complete dataset The current work is leading to create to a complete collection of maps and aerial imagery of Provincia Autonoma di Trento, with a timespan of 160 years. In the perspective of study whose objective is to analyse landscape changes over the years having a complete dataset is a crucial results for the future of the work. The collected imagery covers the whole territory of Trentino, with a high-resolution and detailed scale, as shown in table 3.

1859 maps A partial result is the digitalization of the 1859 cadastrial maps. By following the rules explained in section 2.8 areas of forests and open pastures were classified for the whole region of Trentino.

Orthorectification of the $\mathbf{1 9 5 4}$ dataset A total amount of 92 aerial imagery of the dataset of 1954 aerial images were collected and orthorectified, integrating the imagery of (Cattani, 2015) (Tattoni et al., 2010) (Rocchini et al., 2012) (Maimeri, 2018) was possible to achieve a complete rectified set of imagery from the 1954 dataset for the whole PAT (Gobbi et al., 2018).

Testing the OBIA procedure The OBIA procedure has been calibrated and applied to the whole variety of aerial imagery in the dataset. This result is important because accomplish one of the aims of this project, i.e. to automatize the classification process as much as possible so that its application to large datasets covering the whole Trentino region is feasible (Tattoni et al., 2010) (Cattani, 2015) (Maimeri, 2018). The synergy between Python and GRASS rendered possible to automatize the OBIA in just 140 lines of code.

\section{DISCUSSION AND CONCLUSIONS}

The use of GRASS and QGIS In the course of this research the main tool has been GRASS. The availability of GRASS source code under the GPL was useful especially in the orthorectification phase, where it was crucial to understand how the errors in the GCPs were calculated, accessing the source code of the suite for orthorectification gave insight to the interpretation of the errors (Gobbi et al., 2018). As a matter of fact the two version of GRASS used (6.4 and 7.4) such errors were displayed with two different methods, and understand which one was more significant required accessing to the source code. The possibility to script GRASS with Python is a major advantage in managing large datasets (in terms of number of elements and dimension in GB, see table 3). Once the input parameters are set for a specific analysis, the same module can be sequentially applied to different images with the same parameters. It was possible to apply the same modules sequence in the OBIA procedure with different input parameters with minimum intervention from the user by scripting the algorithm. This approach provides an efficient way of finding an optimum set of parameters of the land use classification procedure. The classification of the complete Trentino territory using OBIA is under way for all the available datasets whith a scripted batch procedure. The effectiveness of this classification OBIA approach will be tested comparing the results with those obtained in the previous works (Cattani, 2015) (Tattoni et al., 2010) (Maimeri, 2018) with the OBIA approach.

Finally, the use of QGIS and its digitizing tools plugin prevented topological errors in the digitalization process of the 1859 dataset, assuring that the created vector files were viable for further analysis.

The future of the research In the current study, the reconstruction of the past forest landscape from landuse classification will be used for landscape and ecosystem services analysis (Ciolli et al., 2019). Following (Ciolli et al., 2012) and (Tattoni et al., 2010), the landuse maps will be used to evaluate landscape metrics using Fragstat or the LeCos suite in QGIS to evaluate parameters that can describe how the forest coverage has changed during the years. Metrics such as the mean forest patch area, for instance, can represent how the forests became more fragmented or compact. This information helps to give an overall view on the fluctuation of the total forest coverage and its density (Campagnaro et al., 2017) (Tattoni et al., 2017) and it will be crucial for mapping the hydro-geological risk (Ciolli et al., 2019).

The second field of application of the forest coverage data is the use of predictors such as Markov Chains to simulate how protected habitats will evolve if the "no human intervention" policy is applied, as specified in (Ciolli et al., 2012).

A total of 142 Sites of Community Importance have been recognized in Trentino: the fate of this areas can be easily protected by human intervention and this study can help to program the actions that can be performed to protect such areas.

\section{ACKNOWLEDGMENTS}

We would gladly thank Luca Delucchi from Fondazione Edmund Mach for the help with GRASS, in particular with the module for the orthorectification. All the aerial imagery were provided by the Provincia Autonoma di Trento, while the cadaster historical map for the Province of Trento has been made available by the Servizio Catasto della Provincia Autonoma di Trento, under the Creative Commons Attribution 4.0 license.

Finally we would like to thank the Ufficio Fauna e Foreste, in the person of Maurizio Miori for providing all the data about forest types in Trentino. 


\section{REFERENCES}

Bouman, C., Shapiro, M., 1992. Multispectral Image Segmentation using a Multiscale Image Model. Proceedings of IEEE International Conference on Acoustoustic, Speech and Sig. Proc., 565-568. http://dx.doi.org/10.1109/ICASSP.1992.226150.

Burnett, C, Blaschke, T., 2003. A multi-scale segmentation/object relationship modelling methodology for landscape analysis. Ecological Modelling, 168, 233-249.

Campagnaro, T., Frate, L., Carranza, M.L., Sitzia, T., 2017. Multi-scale analysis of alpine landscapes with different intensities of abandonment reveals similar spatial pattern changes: implication for habitat conservation. Ecological Indicators, 147159. https://doi.org/10.1016/j.ecolind.2016.11.017.

Cantiani, M.G., Geitner, C., Haida, D., Maino, F., Tattoni, C., Vettorato, D., Ciolli, M., 2016. Balancing economic development and environmental conservation for a new governance of Alpine areas. Sustainability, 802-820. http://dx.doi.org/10.3390/su8080802.

Cattani, G., 2015. Metodologia per la valutazione della perdita di biodiversità dovuta al cambiamento del paesaggio agroforestale: il caso del tesino. Master's thesis, University of Trento.

Ciolli, M., Bezzi, M., Comunello, G., Laitempergher, G., Gobbi, S., Tattoni, C., Cantiani, M.G., 2019. Integrating dendrochronology and geomatics to monitor natural hazards and landscape changes. Applied Geomatics, 11, 39-52. https://doi.org/10.1007/s12518-018-0236-0.

Ciolli, M., Federici, B., Ferrando, I., Marzocchi, R., Sguerso, D., Tattoni, C., Vitti, A., Zatelli, P., 2017. FOSS tools and applications for education in geospatial sciences. ISPRS International Journal of Geo-Information, 6.

Ciolli, M., Tattoni, C., Ferretti, F., 2012. Understanding forest changes to support planning: A fine-scale Markov chain approach. in F. Jordán, S. Jorgensen (edited by), Models of the ecological hierarchy from molecules to the ecosphere. Elsevier, Amsterdam. http://dx.doi.org/10.1016/B9780-444-59396-2.00021-3.

Clewley, D., Bunting, P., Shepherd, J., Gillingham, S., Flood, N., Dymond, J., Lucas, R., Armston, J., Moghaddam, M., 2014. A Python-Based Open Source System for Geographic Object-Based Image Analysis (GEOBIA)utilizing raster attribute tables. Remote sensing, 6, 6111-6135. https://doi.org/10.3390/rs6076111.

De Natale, F., Gasparini, P., A., Carriero, 2005. A study on tree colonization of abandoned land in the Italian Alps: extent and characteristics of new forest stands in Trentino. Proceedings of the IUFRO Congress Sustainable forestry in theory and practice.

Ferretti, F., Sboarina, C., Tattoni, C., Vitti, A., Zatelli, P., Geri, F., Pompei, E., Ciolli, M., 2018. The 1936 Italian Kingdom Forest Map reviewed: a dataset for landscape and ecological research. Annals of Silvicultural Research, 42, 3-19. https://doi.org/10.12899/asr-1411.

Ferretti, F., Sboarina, C., Tattoni, C., Vitti, A., Zatelli, P., Geri, F., Pompei, E., Ciolli, M., 2019. Carta forestale del regno di italia. http://carta1936.dicam.unitn.it. Accessed: 2019-04-29.
Gaitanis, A, Kalogeropoulos, K., Detsis, V., Chalkias, C., 2015. Monitoring 60 Years of Land Cover Change in the Marathon area, Greece. Land, 4, 337-354. https://doi.org/10.3390/land4020337.

Gautam, A.P., Shivakoti, G.P., Webb, E.L., 2004. Forest cover change, physiography, local economy, and institutions in a mountain watershed in Nepal. Environment Managment, 1, 4861. https://doi.org/10.1007/s00267-003-0031-4.

Geoportale Provincia Autonoma di Trento, 2019a. Metadati volo 1973. tn:8cf5ffba-f738-4e60-a0e6-7669919eec24. Accessed: 2019-04-29.

Geoportale Provincia Autonoma di Trento, 2019b. Metadati volo 1994. tn:629ccdc8-e046-411c-95b0-326cb0bdc656. Accessed: 2019-04-29.

Geoportale Provincia Autonoma di Trento, 2019c. Metadati volo 2006. tn:a1dfd067-1f7d-40d1-b873-fc665a61af6b. Accessed: 2019-04-29.

Geoportale Provincia Autonoma di Trento, 2019d. Metadati volo 2015. tn:f2e88f1b-05d9-4942-93ee-857a0a9e1f0b. Accessed: 2019-04-29.

Gobbi, S., Maimeri, G., Tattoni, C., Cantiani, M.G., Rocchini, D., La Porta, N., Ciolli, M., 2018. Orthorectification of a large dataset of historical aerial images:procedure and precision assessment in an open source environment. The International Archives of the Photogrammetry, Remote Sensing and Spatial Information Sciences, XLII-4/W8, 53-59. https://doi.org/10.5194/isprs-archives-XLII-4-W8-53-2018.

Godone, D., Gabarino, M., Sibona, E., 2014. Progressive fragmentation of a traditional Mediterranean landscape by hazelnut plantations: The impact of CAP over time in the Langhe region (NW Italy). Land use Policy, 48-61. https://doi.org/10.1016/j.landusepol.2013.08.018.

GRASS Development Team, 2017. Geographic Resources Analysis Support System (GRASS) Software, Version 6.4. Open Source Geospatial Foundation. grass.osgeo.org (1 November 2017)

GRASS Development Team, 2018. Geographic Resources Analysis Support System (GRASS) Software, Version 7.4. Open Source Geospatial Foundation. grass.osgeo.org (20 September 2018).

Grippa, T., Lennert, M., Beaumont, B., Vanhuysse, S., Stephenne, N., Wolff, E., 2017. An Open-Source Semi-Automated Processing Chain for Urban ObjectBased Classification. Remote Sensing, 4, 358-378. https://doi.org/10.3390/rs9040358.

Haralick, R. M., Shanmugam, K., Dinstein, I., 1973. Textural features for image classification. IEEE transactions on systems,man and cybernetics, 3, 610-621.

MacDonald, D., Crabtree, J., Wiesinger, G., Dax, T., Stamou, N., Fleury, P., Lazpita, J., Gibon, A., 2000. Agricultural abandonment in mountain areas of Europe: environmental consequences and policy response. Journal of Environmental Management, 59, 47-69. https://doi.org/10.1006/jema.1999.0335.

Maimeri, G., 2018. Variazione della copertura forestale in val di fassa tramite analisi gis multitemporale. Master's thesis, University of Trento. 
Ministero dell'ambiente, 2010. Elenco ufficiale delle aree protette (euap). Sixth update, approved the 27th of April 2010, published in the official Gazette (125).

Neteler, M., Bowman, M.H., Landa, M., Metz, M., 2012. GRASS GIS: A multi-purpose open source GIS. Environmental Modelling and Software, 31, 142-130. https://doi.org/10.1016/j.envsoft.2011.11.014.

Neteler, Makus, Mitasova, Helena, 2008. Open Source GIS: A GRASS GIS Approach. Springer, New York.

Novak, Kurt, 1992. Rectification of Digital Imagery. Photogrammetric Engeneering and Remote Sensing, 58, 339-344.

Preatoni, D.G., Tattoni, C., Bisi, F., Masseroni, E., D'Acunto, D., Lunardi, S., Grimod, I., Martinoli, A., Tosi, G., 2012. Open source evaluation of kilometric indexes of abundance. Ecological Informatics, 35-40. http://dx.doi.org/10.1016/j.ecoinf.2011.07.002.

QGIS Development Team, 2019. QGIS Geographic Information System, version 2.18. Open Source Geospatial Foundation.

Rocchini, Duccio, Metz, Markus, Frigeri, Alessandro, Delucchi, Luca, Marcantonio, Matteo, Netler, Markus, 2012. Robust rectification of aerial photographs in an open source environment. Computers and geosciences, 39, 145-151. https://doi.org/10.1016/j.cageo.2011.06.002.

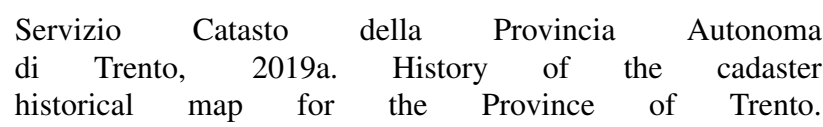
http://www.catasto.provincia.tn.it/cenni_storici/pagina8.html. Accessed: 2019-04-29.

Servizio Catasto della Provincia Autonoma di Trento, 2019b. Mappe storiche di impianto (urmappe). https://www.catastotn.it/mappeStoriche.html. Accessed: 2019-04-29.

Servizio Fauna e Foreste, 2018. Schede dei tipi forestali, caratteristiche e indicazioni gestionali. 1st edn, Provincia Autonoma di Trento, Trento, Via Trener 3.

Sitzia, T., 2009. Ecologia e gestione dei boschi di neoformazione nel paesaggio trentino. Servizio Foreste e Fauna, Provincia Autonoma di Trento, Trento, Italy. pp. 301.

Sitzia, T., Carriero, A., De Natale, F., Gasparini, P., Wolynski, A., Viola, F., 2007. Recent secondary woodlands in a regional sample of southern-alpine abandoned landscapes: implications for restoration ecology and silviculture. Proceedings of the seventh IALE World Congress, 2, 783-784.

Tattoni, C, Ciolli, M, Ferretti, F, Cantiani, M.G., 2010. Monitoring spatial and temporal pattern of Paneveggio forest ( northern Italy ) from 1859 to 2006. iForest, 3, 72-80. https://doi.org/10.3832/ifor0530-003.

Tattoni, C., Ianni, E., Geneletti, D., Zatelli, P., Ciolli, M., 2017. Landscape changes, traditional ecological knowledge and future scenarios in the Alps: A holistic ecological approach. Science of the Total Environment, 27-36. http://dx.doi.org/10.1016/j.scitotenv.2016.11.075.

Van Rossum, G., 1995. Python Library Reference. CWI Report.
Vitti, A., 2012. The Mumford-Shah variational model for image segmentation: An overview of the theory, implementation and use. ISPRS Journal of Photogrammetry and Remote Sensing, 69, 50-64. https://doi.org/10.1016/j.isprsjprs.2012.02.005. 